\title{
"OI IV, COMO VAI? BOA SORTE NA ESCOLA!" NOTAS (AUTO)BIOGRÁFICAS CONSTITUTIVAS DA HISTÓRIA DE VIDA DE UM EDUCADOR
}

IVOR F. GOODSON

https://orcid.org/0000-0001-6839-9490

Guerrand-Hermès Foundation for Peace

MARIA INÊS PETRUCCI-ROSA

https://orcid.org/0000-0002-2504-614X

Universidade Estadual de Campinas

0 artigo trata de relações entre estórias e histórias de vida, abordando para isso possibilidades de interlocução entre ideias já debatidas sobre aprendizagem narrativa e sobre a experiência benjaminiana. Como empeiria, revisita notas (auto)biográficas de um dos autores, originadas de uma entrevista concedida e publicada em 2015, onde sua infância narrada aponta para um tempo futuro no qual o educador mantém seu senso de propósito de justiça social. A história de vida desse educador, agora configurada em mônadas benjaminianas, possibilita reflexões sobre a natureza da (auto)biografia que se fortalece como ponto de partida no sentido da luta por uma educação que favoreça a valorização de aprendizagens tribais transmutadas em aprendizagens narrativas calcadas em sentimentos, sonhos e compaixão. Com essas considerações, pelo menos duas vertentes teórico-metodológicas que operam com conceitos de narrativas são conjugadas: aquela proposta por Ivor Goodson e aquela advinda da contribuição intelectual de Walter Benjamin. Aproximar tais perspectivas de diferentes origens, mas de propósitos convergentes, configura-se numa fecunda oportunidade de pensar a educação como forma de resistência e transformação num mundo marcado pela desigualdade social.

Palavras-chave: Narrativa, História de vida. (Auto)biografia. 


\section{TEACHER'S LIFE HISTORY}

The article deals with relationships between stories and life histories, addressing for this the possibilities of dialogue between ideas already debated about narrative learning and the Benjaminian experience. As empeiria, revisits (auto)biographical notes from one of the authors, originated from an interview published in 2015, where his narrated childhood points to a future time in which the educator maintains his sense of purpose for social justice. His life story, now shaped by Benjamin monads, allows reflections on the nature of (auto)biography that strengthens itself as a starting point for the struggle for an education that favours the appreciation of tribal learning transmuted in narrative learning grounded in feelings, dreams and compassion. With these considerations, at least two methodological-theoretical strands that operate on narrative concepts are combined: that proposed by Ivor Goodson and that coming from the intellectual contribution of Walter Benjamin. Bringing these perspectives together from different origins but with converging purposes is a fruitful opportunity to think of education as a form of resistance and transformation in a world marked by social inequality.

Keywords: Narrative. Life history. (Auto)biography.

\section{RESUMEN}

\section{"HOLA IV, ¿CÓMO ESTÁS? BUENA SUERTE EN LA ESCUELA!" NOTAS (AUTO)BIOGRÁFICAS CONSTITUTIVAS DE LA HISTORIA DE VIDA DE UN EDUCADOR}

El artículo aborda las relaciones entre estorias e historias de vida, abordando así las posibilidades de diálogo entre ideas ya debatidas sobre el aprendizaje narrativa y sobre la experiencia benjaminiana. Como empeiria, revisita las notas (auto)biográficas de uno de los autores, a partir de una entrevista concedida y publicada en 2015, donde su infancia narrada apunta a un momento futuro en el que el educador mantiene su sentido de propósito para la justicia social. La historia de su vida, ahora moldeada por mónadas benjaminianas, permite reflexionar sobre la naturaleza de la (auto)biografia que se fortalece como un punto de partida para la lucha por una educación que favorezca la apreciación del aprendizaje tribal transmutado en el aprendizaje narrativo basado en sentimientos, sueños 
y compasión. Con estas consideraciones, se combinan al menos dos hilos teórico-metodológicos que operan sobre conceptos narrativos: el propuesto por Ivor Goodson y el que proviene de la contribución intelectual de Walter Benjamin. Reunir estas perspectivas desde diferentes orígenes pero con propósitos convergentes es una oportunidad fructífera para pensar en la educación como una forma de resistencia y transformación en un mundo marcado por la desigualdad social.

Palabras-clave: Narrativa. Historia de vida. (Auto)biografia.

\section{Introdução}

Este artigo expressa mais um encontro entre dois educadores que se interessam pelos estudos (auto)biográficos: Ivor. F. Goodson e M. Inês Petrucci-Rosa. Nesse encontro, temos a intenção de promover reflexões acerca das potencialidades da narrativa (auto)biográfica como forma de transformar estórias em histórias de vida, tendo como foco o enraizamento em contextos sociais, históricos, políticos e culturais mais amplos. Para isso, aspectos da biografia de um dos autores - I. F. Goodson - serão apresentados, pois sua história de vida, em consonância com sua obra, constitui importante patrimônio de aprendizagem no campo da Educação, com repercussão mundial. Sua história de vida ressignifica a experiência educacional ao mobilizar aprendizagens (auto)biográficas e recuperar modos coletivos de vida. (SIKES e DOWNES, 2019)

Procuramos demonstrar como a memória (auto)biográfica ajuda a definir e localizar nossas narrativas de identidade pessoal. A (auto) biografia provê orientação para a projeção das ações que investimos ao longo da vida e, assim, torna-se central para a existência humana. As implicações de onde a memória (auto) biográfica se localiza nesse espectro de possibilidades são muito relevantes, considerando seu papel na construção e manutenção da identidade, bem como nas atividades associadas de ensino e aprendizagem.

\section{Das estórias às histórias de vida}

O tempo das "grandes narrativas" do progresso humano se encontra no passado. Como afirma Williams (2005), a partir do século XIX, a relação entre o progresso e as grandes narrativas da história cresceu vertiginosamente. Nos dias de hoje, no entanto, a ideia de grandes grupos discutindo assuntos importantes parece ficar cada vez mais inatingivel. Já no século XX, acompanhamos o colapso das grandes narrativas, tanto nas ciências humanas quanto na psicologia de Freud, nas ciências positivistas, na consciência marxista de classe, entre outros. Com os usos indevidos da tecnologia em práticas relacionadas a genocídios, à eliminação de etnias, ao holocausto e suas câmeras de gás, a história do século XX desmentiu as promessas de progresso material e científico, em sintonia com uma ordem moral superior.

As grandes narrativas passaram por crises profundas de credibilidade. Passamos a acompanhar a emergência de um outro tipo de narrativa, de âmbito bem mais restrito, individualizado, que configura as estórias pessoais. Com a emergência de tais estórias expressas em pequenas narrativas, vimos também certo regresso a princípios antigos e fundamentalistas. No modo de vida contemporâneo, podemos constatar o estabelecimento da narrativa de vidas individualizadas, configurando o que tem sido chamado de a "era da narrativa", marcada por políticas narrativas, de modos nar- 
rativos e de identidades narrativas. Seria até mais correto dizermos que ao contrastarmos o período histórico que vivemos com os séculos que precederam a Idade das Luzes, estamos na "era das pequenas narrativas".

Vemos aflorar, no cenário brasileiro contemporâneo, modos de identidade narrativa marcados por retrocesso e ignorância. Podemos mencionar um exemplo no episódio da declaração do presidente Bolsonaro em relação ao trabalho infantil: "Olha só, trabalhando com 9, 10 anos de idade na fazenda, não fui prejudicado em nada. Quando algum moleque de 9 ou 10 anos vai trabalhar em algum lugar, está cheio de gente aí (falando) 'trabalho escravo, não sei o que, trabalho infantil'. Agora, quando está fumando um paralelepípedo de craque, ninguém fala nada. Então trabalho não atrapalha a vida de ninguém.", disse o presidente'. Ou, ainda, quando o presidente Bolsonaro vem a público e declara que os dados do Instituto Nacional de Pesquisas Espaciais (INPE) acerca do aumento do desmatamento nos últimos anos, em território brasileiro e, em particular, na Amazônia, são mentirosos, e que tais práticas vêm sendo produzidas por aqueles que desejam exercer oposição política a seu governo ${ }^{2}$. Esses são exemplos daquilo que podemos chamar de "política narrativa", produzida a partir de estórias. Como afirmado em Goodson (2015, p. 10), é "tudo uma questão de criar o tipo certo de estória".

O ponto de vista "pessoal", descompromissado com contextos sociais, políticos ou científicos, tem sido construído em alguns países ocidentais como uma versão especial, calcada numa perspectiva individualista e restrita do mundo. "Constitui, pois um ponto de vista irreconhecivel para uma grande parte do res-

1 Notícia veiculada por diferentes agentes de comunicação, dentre eles, o jornal $\mathbf{O}$ Globo, em matéria publicada em 04 de julho de 2019 (MAIA, 2019).

2 Notícia veiculada por diferentes agentes de comunicação, dentre eles, o Portal de Notícias G1, em matéria publicada em 21 de julho de 2019 (LIS, 2019). to do mundo. [...] Obscurecendo os limites do individualismo, tais testemunhos manifestam frequente isolamento e alienação social" (ANDREWS, 1991, p. 13).

Essas são questões que nos mobilizam à medida que a era da narrativa progride. Se as estórias de vida não alcançam contextos socioculturais, tampouco sua localização histórica num dado tempo e lugar, passos largos de retrocesso são dados no que se refere à dimensão política e coletiva mais abrangente.

Defendemos que o escrutínio do contexto histórico é a ferramenta com a qual é possivel enfrentar a questão da individualização e do preconceito. Procurando formas de superação de tal perspectiva, é primordial abordarmos fatores históricos associados ao tempo e ao período dos acontecimentos, rompendo os limites das pequenas narrativas ao entretecermos contextos sociais e políticos mais amplos com as estórias de vida. Tal rompimento caminha na direção do enraizamento das narrativas, assim como propõe Frochtengarten:

O enraizamento pressupõe a participação de um homem entre outros, em condições bastante determinadas. 0 homem enraizado participa de grupos que conservam heranças do passado. Podem ser transmitidas pelas palavras dos mais velhos: um ensinamento, uma sugestão prática ou uma norma. Podem ser recebidas como bens materiais: a paisagem de uma cidade, a terra revolvida pelos ancestrais, a casa por eles habitada ou objetos que revivem feitos de antigas gerações. Em outros termos, diríamos que a participação social do homem enraizado está assentada em meios onde recebe os princípios da vida moral, intelectual e espiritual que irão informar sua existência. (Frochtengarten, 2005, p. 368). Para investirmos num trabalho de tecer narrativas (auto)biográficas enraizadas como forma de aprendizagem de vida, é necessário não cairmos nas armadilhas de individualização e descontextualização. Dessa forma, parece-nos fundamental uma compreensão do contexto histórico e social, recolhendo estórias de vida que se transformam em histórias de 
vida ao serem narradas em processos colaborativos, à medida que incorporam informações, dados e outras versões advindas de processos de contextualização. Como afirmado em Goodson (2015), ao nos deslocarmos das estórias de vida para as histórias de vida completas, incorporando a análise do curso de vida, estamos valorizando o potencial para a compreensão do modo como o tempo e o contexto demarcam as "vidas de aprendizagem" das pessoas, com foco na inserção a narrativa de vida individual num contexto coletivo. Nesse processo, procuramos emendar a ruptura entre a narrativa de vida individual e a experiência coletiva e histórica.

Com essa aposta nas potencialidades das "vidas de aprendizagem", que buscam inserir a narrativa individual num tempo e lugar coletivo e histórico, passamos a apresentar notas (auto)biográficas de um dos autores. Essa iniciativa se justifica à medida que se trata de um educador com uma trajetória de mais de quarenta anos no campo da educação, com uma obra de repercussão mundial (SIKES e DOWNES, 2019).

\section{A abordagem teórico- metodológica proporcionada pelas mônadas}

Narrativas são maneiras de relatar nossas experiências, que podem ser materializadas no que chamamos de mônadas, movidos pela inspiração produzida pela leitura de A Infância em Berlim por Volta de 1900 (BENJAMIN, 2007).

Mônadas são fragmentos narrativos imagéticos, que exibem os matizes de um todo, da mesma forma como ocorre com um caleidoscópio. Na relação entre sua natureza fragmentária e o universal, que a mônada é constituída por um elemento temporal de paralisação e de congelamento do fluxo da história, como um flash ou snapshot ${ }^{3}$, guardando em si uma tensão.

3 Emprestamos aqui a expressão snapshot utilizada por José Machado Pais (PAIS, 2003).
Movendo-se em um caleidoscópio, a mônada é partícula que junto a outras, traz possibilidades de compreensão de contextos sociais, culturais e políticos. Para Benjamin, apoiado em Leibniz, cada mônada pode ser um "espelho do universo", que harmoniza em si o infinito e o particular (BENJAMIN, 2007). No texto Infância em Berlim por volta de 1900, Benjamin apresenta uma série de pequenas narrativas que remetem à sua infância, nas quais, vislumbra-se a articulação entre o vivido particular e esferas sociais mais amplas, resgatando a experiência do passado infantil, ressignificado a partir do olhar adulto. 0 sujeito que ali se revela é imbuído de uma dimensão social ampliada, pois, como afirma Jeanne-Marie Gagnebin, "renunciando à clausura tranqüilizante, mas também à sufocação da particularidade individual, é atravessado pelas ondas de desejos, de revoltas, de desesperos coletivos" (GAGNEBIN, 2004, p. 7475). Os pequenos textos memorialísticos são chamados de mônadas, à medida que refletem em suas particularidades os elementos desse universo social.

A mônada revela-se como uma chave para que se mantenha o equilíbrio entre um individualismo idiossincrático e hermético, que não se comunica com o mundo exterior, e uma consciência social ilusória que pretenda abarcar os sujeitos desprezando suas especificidades. Nesse sentido, a mônada pode revelar o caráter singular da experiência educativa realizada, sem perder de vista suas articulações com o universo amplo da cultura em que ela está imersa e com o olhar subjetivo do pesquisador. (PETRUCCI-ROSA e col., 2011, p. 205)

Do ponto de vista benjaminiano, a narrativa ressignifica própria experiência, na relação entre o eu e o outro, fortalecendo a ideia de que narrar é aconselhar. Operar com narrativas não é produzir relatórios repletos de informações a serem classificadas ou categorizadas. 
Esses são os princípios assumidos na abordagem teórico-metodológica que sustenta a nossa análise. Na perspectiva analítica, é importante considerar que para Benjamin (2007) quem adensa a narrativa é o ouvinte, o que implica assumir a busca de densidades temáticas (GOODSON, 2013) que emergem a partir dos episódios narrados em diferentes abrangências e profundidades. Com esse princípio metodológico, organizamos os fragmentos narrativos compondo um "retrato", onde as densidades temáticas se evidenciam conjugadas com possibilidades imagéticas sobre 0 que é narrado. Outro aspecto importante a ser destacado no modo analítico da escuta das narrativas, é considerar os enraizamentos das histórias de vida em contextos sociais mais amplos.

\section{Notas (auto)biográficas do educador}

Scherto Gill ${ }^{4}$ realizou uma entrevista ${ }^{5}$ com Ivor, escutando sua narrativa de vida a partir de episódios marcantes que retratam com suas escolhas e com os acontecimentos que, de certa forma, definiram sua trajetória de educador. Passaremos a apresentar trechos dessa entrevista, como mônadas (BENJAMIN, 1987; PETRUCCI-ROSA e col., 2011), a fim de mobilizarmos os aspectos mais importantes que adensam sua estória, tornando-a história de vida.

O conjunto de dezesseis mônadas apresentado a seguir delineia um retrato narrativo do educador, marcado por uma densidade temática constituída de eventos, escolhas, sensibilidades e decisões. (Goodson, 2013)

4 Dr. Scherto Gill é pesquisadora visitante na University of Sussex e no GHFP- U.K.

5 A entrevista na íntegra está publicada no artigo Exploring History and Memory through Autobiographical Memory, publicado na revista Historia y Memoria de la Educación 1 (2015): 265-285

\section{Retrato Narrativo de Ivor}

\section{Mônada 1}

Detalhes da vida

Penso que há certas continuidades no meu senso de propósito e na minha busca por significado e, como diz Francesca, do filme As Pontes de Madison (1995), de Clint Eastwood, é sempre uma combinação de detalhes diários: os detalhes da vida. No filme, ela fala sobre sonhos maravilhosos e, em seguida, volta aos detalhes de sua vida e os abraça. Eu diria que há muitos detalhes em minha vida, mas o que os une é uma espécie de continuidade de anseios em torno de questões de justiça social, igualitarismo - tratando as pessoas igualmente diariamente e também ideologicamente. Portanto, existe uma espécie de continuidade de crença, desde o início em que isso começou. Essa crença de que as pessoas devem ser tratadas igualmente certamente começou nas minhas origens, que estavam nas margens da sociedade inglesa. Se você é filho de um trabalhador braçal, está até certo ponto à margem do sistema neste país, e esse sentimento de marginalidade é uma grande sorte em muitos aspectos. Uma das vantagens, penso, é transformar o que pode parecer infortúnio social em um enorme ganho, porque é claro que isso lhe dá um grande impulso para entender o centro.

\section{Mônada 2}

Não havia livros em casa

Cresci em uma casa onde não era ensinado a ler. Uma das razões pelas quais eu nem pensava em ler é que não havia livros em casa. Meu pai tinha problemas com leitura, não lia realmente. Minha mãe lia um pouco, mas não lia para mim e não achava importante me ensinar a ler, porque pensava, de várias maneiras, que era a narrativa e a cultura oral que identificavam nosso grupo. Então aprendi a ser um bom contador de histórias, não um lei- 
tor. Portanto, um aspecto da marginalidade é esse sentimento de empoderamento precoce, se você vê a leitura como empoderamento, a alfabetização como empoderamento.

\section{Mônada 3}

\section{Cansado}

Eu não via muito meu pai porque ele trabalhava seis dias por semana, às vezes até no domingo de manhã. Estava sempre cansado quando chegava em casa e, portanto, não falava muito porque estava constantemente exausto. A única vez em que eu o via com mais frequência era nas férias de uma semana por ano. Minha mãe trabalhava como garçonete ou na fábrica de munições, o que também fazia com que eu não a visse muito.

\section{Mônada 4}

\section{A fábrica como destino}

Até os seis anos de idade eu não frequentava a escola, não confiávamos particularmente nas escolas da minha vila. As escolas eram um lugar onde todos frequentavam e todos fracassavam. No final, o destino era uma fábrica de qualquer maneira. Havia uma profunda desconfiança nas escolas na comunidade em que cresci. É isso que representa a marginalidade. Isso significa que todas as crenças da sociedade - de que a alfabetização é uma coisa boa, a educação é uma coisa boa, as escolas são uma coisa boa e assim por diante - não funcionam porque não são acessiveis às pessoas à margem.

\section{Mônada 5}

\section{Grande apreciador da rua}

Eu era filho único, meu pai era único filho homem com doze irmãs e minha mãe era uma entre oito... Nossa casa era uma moradia de tamanho razoável. Papai era um trabalhador muito atencioso e consciente. Então, de certa forma, éramos uma família respeitável da classe trabalhadora. o que mais me lembro dessa casa era a imagem de papai dormindo na poltrona depois de um dia de trabalho; mamãe provavelmente no trabalho ou conversando com vizinhos e eu provavelmente fora, na maior parte do tempo. Eu era um grande apreciador da rua!

\section{Mônada 6}

\section{Pequenos atos delinquentes}

Passei muito tempo indo a um centro de recreação. A partir das sete, todas as noites, eu estava lá, jogando futebol, jogando cartas, brincando, fazendo coisas levemente transgressoras. Tive problemas com a polícia algumas vezes por fazer algazarras - serrando a bicicleta do mestre escoteiro ao meio, por exemplo, e observando encantado quando ele subiu nela e metade dela quebrou... A polícia apareceu para averiguar... Havia todo tipo de pequenos atos delinquentes. Era um garoto razoavelmente orientado para a rua, um garoto bastante rude, e todos os meus amigos eram exatamente iguais.

\section{Mônada 7}

Diferente dos meus amigos da escola

Aprendi a ler quando tinha oito anos, porque o professor foi até minha casa e disse à minha mãe e ao meu pai que eles deveriam tentar me ensinar a ler, que deveriam comprar alguns livros para mim. Logo, aprendi a ler e comecei a adorar ler, tornando-me diferente dos meus amigos da escola. Todos os amigos da rua foram para a escola local, que era uma escola secundária moderna à época, e eu passei no $11^{+6}$, para meu próprio espanto e para o espanto de todo mundo. Acredito que só havia uma outra pessoa em nossa vila já havia passado no $11^{+}$.

6 Nesse período, o exame $11^{+}$(eleven plus) era destinado a estudantes do último ano do ensino primário, para ingresso nas escolas secundárias que utilizavam a seleção acadêmica. 


\section{Mônada 8}

\section{Lone Pine 5}

Lembro-me do cheiro das tábuas da biblioteca em que minha mãe me levou para pegar o primeiro livro. Lembro-me do primeiro livro de Leonard Gribble que tirei da prateleira e li. Lembro-me do cheiro e da excitação que os livros provocavam em mim. Lembro que minha mãe me levou à William Smith, uma livraria, para comprar livros, porque meus pais foram instruídos a me comprarem livros. Tive permissão para escolher dois livros. Comprei o Lone Pine 5, de Malcolm Saville, que ainda tenho, e me lembro de estar sentado e lendo... Há uma brecha entre esse garoto desleixado das ruas, de nariz arrogante, que adorava brincar com bolas de futebol e sair com garotas, e esse outro que ficava sozinho, lendo, absolutamente absorvido no mundo de Lone Pine 5, sendo transportado para outro lugar por um livro. Portanto, desde o início, existe uma estranha dupla face em minha personalidade, que continua até hoje: de um lado está esse grande amor pela vida de rua romântica e transgressora, e, do outro, um tipo acadêmico profundamente isolado e fechado em si mesmo. Ambos são parte de mim.

\section{Mônada 9}

\section{Filho único}

Minha mãe era uma mulher profundamente inteligente, como era meu pai de certa forma, mas ela realmente adoraria ter tido uma vida acadêmica criativa. Sempre tive consciência disso e eu ficava com muita pena da frustração que ela sentia com sua vida. Quando ela chegou aos 104 anos, ainda estava tentando encontrar uma maneira de ser criativa. Então, de certa forma, acho que meu projeto de vida estava parcialmente relacionado ao sentimento de frustração dela, e parcialmente guiado por ele, também. Portanto, cada um dos meus pais, que são muito queridos por mim (obviamente, quando você é filho único, conhece seus pais dessa maneira específica), influenciou a maneira como respondi. As dificuldades que as passagens de fronteira colocavam eram consideráveis na família da classe trabalhadora.

\section{Mônada 10}

«Oi IV, como vai? Boa sorte na escola!»

O maior problema, é claro, era a reação dos meus companheiros e, provavelmente, entender a continuidade do meu sentido de identidade. Pensar sobre como é ser o único garoto da vila que veste um casaco azul turquesa com um chapéu amarelo com pingentes, para atravessar a zona rural para ir à escola. Ainda posso ouvi-los gritando "verme secundarista" e jogando bolos de lama em mim no meu primeiro dia de ir à escola. $E$, é claro, no segundo dia, tirei o casaco, tirei o chapéu e fui para a escola. o que sempre pude de alguma maneira fazer foi enfrentar essa reação, que é um medo coletivo da alteridade. Lá, a tribo estava expressando que um dos desertores estava tentando escapar e esse era eu, que tinha sido selecionado para fazer isso. E como lidei com isso? Suponho que essa é a chave para me entender agora: apenas lidei com isso! Dentro de semanas, eu estava entrosado com eles novamente e nunca mais fizeram aquilo. Na verdade, meus melhores amigos, quando eu consegui passar na universidade, costumavam me levar para beber e não me deixavam pagar - eles diziam que era para eu conseguir permanecer na universidade. Assim, meio que encontrei uma maneira de negociar minha diferença e, provavelmente, tenho um senso exagerado de valorizar pessoas assim - pessoas comuns que podem lidar com a sua diferença e, em certo sentido, sua rota de fuga e lidar com isso com tanta beleza. Desde então, estou tentando honrar essas pessoas. Valoriza- 
va a reação deles porque tinha um ambiente generoso. Se estivesse tentando escapar, consideraria somente os bolos de lama, mas em semanas o cumprimento era: "Oi Iv, como vai? Boa sorte na escola!". E essa negociação, essa capacidade de carregar as pessoas com você, é algo que acho que aprendi.

\section{Mônada 11}

\section{Solidariedade e sucesso}

Nasci em 1943, por isso, estamos falando da Inglaterra no início dos anos 50 , um país muito, muito pobre, com enorme solidariedade entre as comunidades da classe trabalhadora e um propósito de auto empoderamento. Em 1945, o governo trabalhista valorizava as pessoas comuns e tentava construir um mundo para elas, com um sistema de assistência social; tentava construir escolas e hospitais que seriam bons para todos. Existia um forte sentimento de uma classe de pessoas que estavam progressivamente vencendo. Portanto, a mobilidade social nesse contexto é um movimento bastante impar e eu diria que, de certa forma, ainda é. No entanto, agora você enfrenta uma situação em que esse sentimento de solidariedade e sucesso de classe foi desmantelado como as fábricas. Então, agora, tudo o que você enfrenta é uma espécie de classe baixa empobrecida, a qual todos gostariam de evitar. Mas naqueles dias, não.

\section{Mônada 12}

\section{A moto, as roupas, as namoradas}

Tinha 15 anos. Queria ir para a universidade? Certamente não, porque todos os meus companheiros estavam voltando para casa com bons salários da fábrica enquanto eu estava andando em uma bicicleta de segunda mão. Todos tinham grandes motos com namoradas nas garupas e roupas de última moda. Tinham tudo o que eu queria: a moto, as roupas, as namoradas. Era apenas o garoto da es- cola primária, ainda andando de bicicleta pela zona rural, que não tinha um centavo no bolso quando saía com meus amigos: eles precisavam comprar as bebidas, pagar a comida. Não, eu não me sentia nada inteligente. Então, o que fiz aos 15 anos? Deixei a escola para trabalhar em uma fábrica. Na verdade, não me sentia privilegiado como garoto de escola secundária, exceto pela pura alegria de aprender que nunca me deixou.

\section{Mônada 13}

\section{Casacos azuis}

A escola ficava entre Wokingham e Egeley, ambas áreas de classe média bastante respeitáveis. Portanto, apenas algumas pessoas vieram das margens das vilas da classe trabaIhadora ou das zonas rurais. Provavelmente cinco por cento das crianças da escola eram da minha tribo. Existiam sinais que indicavam isso. Havia dois lugares para comprar o casaco do uniforme: na Jacksons, que era uma fornecedora de alta classe, ou na Co-operative. Então, desde o início, era evidente quem eram os cinco por cento e, muito rapidamente, os casacos azuis de má qualidade perderam o azul e ficaram esfarrapados, de modo que tudo ficou claramente marcado.

\section{Mônada 14}

O nosso " $h$ "

$\mathrm{Na}$ minha turma, havia um outro garoto que falava com sotaque bem claro de Berkshire, onde soltava seus " $h$ ", e é assim que conversávamos. Eu adorava telefonar para meu pai e conversávamos assim. Até certo ponto, perdi esse sotaque, mas, como digo, quando estou bêbado, volto direto a ele. Portanto, obviamente, um processo de edição aconteceu com meu sotaque. Mas éramos os dois garotos da escola que falavam assim, constantemente sendo instruídos a evitarmos o nosso ' $h$ ' e a não falarmos assim. 


\section{Mônada 15}

\section{Professores desviados}

Em inglês, eu não falava do jeito que eles queriam, por isso falhei. Não aceitaria essa gramática e não perderia meu dialeto. Em outras palavras, não trairia minha tribo. Simplesmente não faria. Sempre fui teimoso assim. É mais complicado do que isso, porque dois ou três dos professores da escola não eram professores convencionais de gramática. Eles eram socialistas. Um deles era um socialista galês, Dai Rees, que era um homem realmente brilhante. 0 outro deles era Joe Petit, coordenador da campanha local pelo desarmamento nuclear. Portanto, havia dois ou três professores desviados dentro da escola que queriam desesperadamente levar as crianças da classe trabalhadora adiante.

\section{Mônada 16}

\section{Selvagens nobres}

De fato, depois que saí da escola aos 15 anos para trabalhar na fábrica, Dai Rees veio à fábrica e me pediu para voltar à escola. Ele meio que me adotou. Há cerca de vinte anos, falei com ele para agradecê-lo por tudo e ele disse: "Cristo, você era uma criança dificil, mas era inteligente! Pude ver que você era um selvagem nobre e estava determinado a não fracassar, estava decidido que eles não o forçariam a sair". Portanto, quero dizer que não existia um sistema monolítico de classe social para nos purificar, a reprodução da classe média, mas havia alguns professores, como sempre existem, que estavam preparados para se rebelar contra isso e para tentar nutrir alguns dos selvagens nobres da classe trabalhadora que se arrastavam pela porta. Então havia um grupinho de nós, mas eu era o único que se destacava. Fui o único que foi para o sexto ano e depois o único que foi para a universidade. Adorei o sexto ano, adorei absolutamente! Era algo que eu não conseguia sufocar em mim mesmo, embora pudesse perceber todas as implicações sociais, não consegui sufocar meu profundo fascínio pelo aprendizado.

\section{História de vida, possibilidades da aprendizagem narrativa e experiência benjaminiana}

Defendemos que uma experiência curricular que considerasse sonhos, dilemas e desejos das crianças e dos jovens possibilitaria a superação do presenteísmo e do individualismo, fortalecendo um propósito de futuro coletivo e social. A aprendizagem narrativa pode ser vista como fundamental para a compreensão de um modo diferente de produção de conhecimento. Se a escola passasse a exercer esse papel no âmbito da cultura e da política, não restaria espaço para um currículo previamente estruturado e definido sem diálogo com as histórias de vida. Uma saída possivel é o favorecimento da aprendizagem narrativa, definida como o aprender a ser um ser social, aprender sobre si mesmo e sobre o mundo. As mônadas do retrato narrativo de "Iv" demonstram essa nossa asserção.

A passagem para essa forma de aprendizagem parece nos aproximar daquilo que Benjamin chama de "experiência". A matéria-prima do narrador é a experiência (Erfahrung), dimensão artesanal da vida, que se torna potente para a aprendizagem narrativa.

Benjamin configura a origem do narrador (Erzähler) em duas figuras: a do camponês, morador de um lugar e conhecedor das tradições; e a do viajante, que traz histórias insólitas de lugares longínquos. Para ele, a conjunção dessas duas figuras possibilitou um modo de produção de conhecimento, na Idade Média, em função da forma como as pessoas circulavam entre as cidades. Nesse sentido, a partir dessas considerações, é possivel definir que o narrador tradicional é resultado da conjunção 
entre o saber do camponês sedentário e o saber do estrangeiro, diferentes em tudo, menos na capacidade de transmitir a experiência.

A trajetória da criança e do jovem filho da classe trabalhadora - que, inserido no contexto do trabalho na fábrica, ressignifica seu contexto social e se torna um educador crítico e comprometido com causas relacionadas a solidariedade, sonhos e missões - é uma experiência de lugares e tempos distantes que se conjugam com as histórias que o intelectual narra e vive em seu contexto de produção. Em sua obra, o saber do camponês sedentário se articula com o conhecimento do estrangeiro (PETRUCCI-ROSA, 2019).

As mônadas aqui apresentadas refletem o que Benjamin conceitua como "experiência", o que chamaríamos de aprendizagem tribal. Essa é a maneira indígena de saber que é transmitida frequentemente em forma de história entre os membros de uma tribo. Há muitos exemplos de aprendizagens proporcionadas pelos pais na narrativa. A aprendizagem tribal vai além das conversas dos pais - é parte da maneira de conhecer e de aprender, incluindo aprendizados com amigos na rua, na vila e na vida em geral. A aprendizagem tribal é como conhecemos o mundo antes de encontrarmos as forças da socialização representadas, em certo sentido, pela escola e pela cultura em geral. Assim, pode ocorrer um conflito entre a aprendizagem tribal, que nos diz quem somos e quem fomos, e qual foi o nosso passado ancestral e qual é o nosso futuro e as forças da socialização representadas pela escola e pela cultura dominante.

Por que isso é muito importante para a educação? Porque, com muita frequência, particularmente na compreensão da "pedagogia do oprimido" (FREIRE, 1987), a diferença entre aprendizagem tribal e aprendizagem escolar é o dilema central que os professores enfrentam.
O futuro que postulamos para esse conflito ao longo da vida - entre o aprendizado tribal e a socialização escolar - é a "aprendizagem narrativa". O que queremos dizer com isso? Queremos dizer que o professor permanece como um mediador independente entre a aprendizagem tribal e a aprendizagem escolar. E se tiverem sucesso, o professor procurará mediar construindo uma narrativa que leve o aluno para outro lugar, e é isso que queremos dizer com "aprendizagem narrativa" e a herança do "capital narrativo". É muito diferente do intercâmbio simbólico normal que ocorre na escola, que usualmente se configura como uma transmissão unidirecional direta da cultura dominante representada pela disciplina escolar e pelo professor para a criança, sem qualquer mediação ou reconhecimento de qualquer aprendizagem tribal que a criança já tenha.

Para Benjamin, transmitir a experiência não é apenas repetir uma história, mas também transmitir às futuras gerações os saberes de suas vivências, como é possivel em um currículo narrativo (GOODSON, 2007). A narrativa sempre tem uma dimensão utilitária (BENJAMIN, 2007). Ao narrador se atribui a capacidade de transmitir sua experiência de forma útil e, numa dimensão mais elaborada, como um conselho. Nesse sentido, a narrativa ensina.

Contar histórias sempre foi a arte de contá-las de novo, e ela se perde quando as histórias não são mais conservadas. Perde-se porque ninguém mais fia ou tece enquanto ouve a história. Quanto mais o ouvinte se esquece de si mesmo, mais profundamente se grava nele o que é ouvido. Quando o ritmo do trabalho se apodera dele, ele escuta as histórias de tal maneira que adquire espontaneamente o dom de narrá-las. Assim se teceu a rede em que está guardado o dom narrativo. E assim essa rede se desfaz hoje por todos os lados, depois de ter sido tecida, há milênios, em torno das mais antigas formas de trabalho manual (BENJAMIN, 2007, p. 91). 
Com as tecnologias contemporâneas, veIhas fronteiras desapareceram. Podemos escrever juntos estando em diferentes lugares no Brasil e na Inglaterra, entretecendo nossas histórias. Toda a noção de espaço está sendo redefinida, e Benjamin nos alertaria para sermos sensiveis a isso, pois muitas dessas fronteiras não estão relacionadas ao espaço externo, mas sim ao interior das pessoas. São lugares secretos onde as pessoas decidem sobre os próprios modos de julgamento, decidem quem elas são, decidem quem querem ser e decidem sobre seus projetos de identidade.

No memorial em homenagem a W. Benjamin, erguido no pequeno vilarejo de Portbou, na Espanha7, próximo à fronteira com a França, há a seguinte inscrição: "a construção histórica concentra-se na memória daqueles que não têm um nome".

Para nós, uma questão emergente é: para quem produzimos conhecimento? Tradicionalmente, as pesquisas são feitas para as pessoas, ao contrário de serem desenvolvidas com as pessoas, que poderiam ser identificadas como os "sem nome": migrantes, sem-teto, mulheres, crianças etc. Se trabalhamos com elas em diálogo permanente, a pesquisa passa a produzir uma aprendizagem narrativa, que é colaborativa. Há um grupo que precisa muito aprender - não os "sem nome" - mas os exploradores que cometem violência com os "sem nome". Os poderosos precisam aprender mais (GOODSON, 2007, p. 69)

Certamente, os poderosos não precisam aprender a operar o poder, pois isso já sabem. No entanto, precisam aprender a exercê-lo de forma compassiva. Não é possivel concebermos um mundo onde o poder não exista, pois ele é parte da condição humana. Por exemplo, em uma situação de aprendizagem colabora-

7 Memorial de autoria do artista israelista Dani Karavan, inaugurado em 1994, em homenagem a Walter Benjamin, na localidade onde aconteceu seu falecimento (PASAJES KARAVAN, s.d.). tiva, o professor é o mais poderoso do grupo. Prover a maioria das pessoas com uma vida razoável, pagar às pessoas mais pobres um salário digno, são demandas possiveis e exequíveis que se apresentam aos ricos do mundo. Isso não seria uma coisa absurda, pelo contrário, poderia ser o custo de alguns foguetes espaciais produzidos nos Estados Unidos. Em outras palavras, seria o suficiente para permitir acesso a todas as pessoas no mundo a uma alimentação necessária e suficiente, bem como a uma educação razoável. Num mundo de absoluta inexpressão, descompaixão, desconsideração, anticristão, anti-islâmico, isso aconteceria? É inadmissivel constatarmos que aqueles que têm tanto não estejam preparados para darem um pouco. A compaixão seria uma forma generosa de exercer o poder que usualmente é ganancioso e profundamente implacável.

Há relações possiveis entre uma cultura ética e uma educação estética, que abrangem essas aspirações de ações sociais. Há uma estética humana que permite às pessoas o contato com suas emoções, seu espírito e sua alma, revestindo-as de bondade. A questão central é compreendermos os limites postos entre cultura, educação e ensino, a ponto de não conseguirem entrar em contato com os sentimentos e as emoções.

Com essas considerações, deparamo-nos com o desafio de desenvolvermos experiências educacionais e intelectuais que permitam às pessoas se aproximarem mais de suas emoções e de seu espírito.

\section{À guisa de conclusão}

Neste artigo, apresentamos questões relacionadas aos modos de vida contemporâneos, ressaltando especialmente a emergência da era das pequenas narrativas e seus efeitos negativos sobre as práticas voltadas para a 
justiça social. Apresentamos, também, apontamentos (auto)biográficos de um dos autores, com o intuito de demonstrar a potencialidade da narrativa que se configura como história de vida, à medida que dialoga com um tempo histórico e um contexto social mais amplo.

Com esses apontamentos, defendemos a emergência e a consolidação de práticas curriculares voltadas para a aprendizagem narrativa, que ao romper com as estórias e firmar as histórias, estabelecem os processos colaborativos como eixo de uma educação estética apoiada numa cultura ética.

Nesse contexto, padrões de individualidade podem se transformar e mudar a natureza da existência humana. Mesmo que nossas narrativas sejam reconstruídas, pelo menos em parte, no interior de nossas mentes, elas também serão negociadas no espaço social. A centralidade das narrativas individuais nas novas políticas, na economia e na nova arena tecnológica apontam para o papel absolutamente vital na negociação do nosso futuro social. (Goodson, 2013)

Esse é o meio no qual as pessoas agora vivem. Para lutar contra a captura das narrativas individuais na nova ordem mundial, é vital compreendermos nossos recursos narrativos. Nosso capital narrativo necessita ser empregado e desenvolvido para relacionar narrativas pessoais a outras de propósito social mais amplo. Nesse sentido, esse capital necessitará ser estendido ao recorrente individualismo que as novas economias flexíveis estão demandando, pois, no novo futuro social, nossas capacidades narrativas carregam uma das possibilidades de perspectiva que nosso mundo poderá vir a ter.

\section{Referências}

ANDREWS, M. Lifetimes of commitment: Ageing, politics and psychology. London: Routledge, 1991.
AS PONTES de Madison [The Bridges of Madison County]. Direção de Clint Eastwood. Universal City, Califórnia: Amblin Entertainment e Malpaso Productions, 2005. 1 DVD (135 min.).

BENJAMIN, W. The Storyteller. In: BENJAMIN, W. Illuminations. New York: Schoken Books, 2007. p. 83-110.

FREIRE, P. Pedagogia do oprimido. 17. ed. Rio de Janeiro: Paz e Terra, 1987.

FROCHTENGARTEN, F. A memória oral no mundo contemporâneo. Estudos Avançados, São Paulo, v. 19, n. 55, p. 367-376, set./dez. 2005. Disponivel em: <http://www.scielo.br/scielo.php?script=sci_arttext\&pid=S0103-40142005000300027>. Acesso em: 12 mar. 2020.

GAGNEBIN, J. M. História e Narração em Walter Benjamin. São Paulo: Perspectiva, 2004.

GALZERANI, M. C. B. Imagens Entrecruzadas de infância e de produção de conhecimento histórico em Walter Benjamin. In: FARIA, A. L. G.; DEMARTINI, Z. B. F.; PRADO, P. D. (Orgs.). Por uma cultura da infância: metodologias de pesquisa com crianças. Campinas: Autores Associados, 2002. p. 49-68.

GOODSON, I. F. Currículo, narrativa e o futuro social. Revista Brasileira de Educação, Rio de Janeiro, v. 12, n. 35, p. 241-252, maio/ago, 2007. Disponivel em: $<$ http://www.scielo.br/scielo.php?script=sci_arttext\&pid=S1413-24782007000200005>. Acesso em: 12 mar. 2020.

GOODSON, I. F. Developing Narrative Theory: Life Histories and Personal Representation, London: Routledge, 2013.

GOODSON, I. Explorar la historia y la memoria a através de la memoria autobiográfica. Historia y Memoria de la Educación, Sociedad Española de Historia de la Educación, 1, 2015. p. 263-284.

GOODSON, I. F. Narrativas em Educação: a Vida e a Voz dos Professores. Porto: Porto Editora, 2015.

LIS, L. Bolsonaro diz que divulgação de dados sobre desmatamento prejudica o Brasil. G1 [on-line], 21/07/2019. Disponivel em: <https://g1.globo.com/ politica/noticia/2019/07/21/bolsonaro-diz-que-di- 
vulgacao-de-dados-sobre-desmatamento-prejudica-o-brasil.ghtml>. Acesso em: 12 mar. 2020.

MAIA, G. Bolsonaro defende trabalho infantil, mas diz que não propõe descriminalização para não ser 'massacrado'. 0 Globo [on-line], 04/07/2019. Disponivel em: <https://oglobo.globo.com/economia/ bolsonaro-defende-trabalho-infantil-mas-diz-quenao-propoe-descriminalizacao-para-nao-ser-massacrado-23785170>. Acesso em: 20 mar. 2020.

PASAJES KARAVAN. La obra. Walter Benjamin a Portbou [on-line], s.d. Disponivel em: <https://walterbenjaminportbou.org/pasajes-karavan/>. Acesso em: 12 mar. 2019.

PETRUCCI-ROSA, M.I., RAMOS, T., SOARES JR, A., CORREA, B. Narrativas e Mônadas: potencialidades para uma outra compreensão de currículo. Currículo sem Fronteiras, v.11, n.1, p.198-217, Jan/Jun, 2011. Disponìvel em http://www.curriculosemfronteiras.org/vo-
L11iss1articles/rosa-ramos-correa-junior.pdf Acessado em: 10/08/2019.

PETRUCCI-ROSA, M.I. Narrative theory and narrative curriculum: steps of resistance and refraction. In: DOWNES, Y., SIKES, P. Storying the Public Intellectual - Commentaries on the Impact and Influence of the Work of Ivor Goodson, $1^{\text {st }}$ Edition, London: Routledge, 2019.

SIKES, P., DOWNES, Y. Storying the Public Intellectual - Commentaries on the Impact and Influence of the Work of Ivor Goodson, $1^{\text {st }}$ Edition, London: Routledge, 2019.

WILLIAMS, H. Cassel's Chronology of World History: Dates, Events and Ideas that made History. London: Cassel, 2005.

Recebido em: 25.10.2019

Revisado em: 12.03.2020

Aprovado em: 20.03.2020

Ivor. F. Goodson trabalha na Guerrand-Hermès Foudation for Peace em Brighton - U.K. Desenvolve pesquisas e estudos, há cerca de 40 anos, sobre questões importantes e cruciais do campo da Educação, em termos de políticas educacionais, estudos históricos das disciplinas escolares, teorias narrativas, estudos de história de vida, profissionalismo e carreira docente (www.ivorgoodson.com). Já trabalhou em instituições de pesquisa educacional em vários países como EUA, Canadá, Estônia, entre outros, além da Inglaterra. E-mail: ivorgoodson@gmail.com

Maria Inês Petrucci-Rosa é Livre-Docente em Educação Escolar, é professora Associada no Departamento de Ensino e Práticas Culturais da Faculdade de Educação da Universidade Estadual de Campinas. Atua nos Programas de Pós Graduação em Educação e Multiunidades em Ensino de Ciências e Matemática, desenvolvendo pesquisas com temáticas relacionadas a narrativa, currículo, políticas curriculares e histórias de vida. Coordena o Grupo de Estudos de Práticas Curriculares e Narrativas Docentes (www.geprana.com) e é bolsista Produtividade CNPq, nível 2. E-mail: minespetrucci@ gmail.com 